Research Article

\title{
Effect of Emamectin Benzoate with Leaf Extracts of Parthenium hysterophorus and Moringa oleifera on the Digestibility and Survival Indices of Spodoptera litura (Lepidoptera: Noctuidae)
}

\author{
Muhammad Irfan Ullah ${ }^{1 *}$, Sana Majeed ${ }^{1}$, Muhammad Arshad ${ }^{1}$, Nimra Altaf ${ }^{1}$, Muhammad Luqman ${ }^{2}$, \\ Asad Abdullah ${ }^{1}$ and Muhammad Afzal ${ }^{3}$ \\ ${ }^{1}$ Department of Entomology, University of Sargodha, 40100, Sargodha, Pakistan; ${ }^{2}$ Department of Agricultural Extension, \\ University of Sargodha, 40100, Sargodha, Pakistan; ${ }^{3}$ Baba Guru Nanak University Nankana Sabib, Pakistan.
}

\begin{abstract}
Botanical insecticides are an environment-friendly approach and have been used in integrated pest management for various insect pests. Here we tested the effect of emamectin benzoate 1.9\% EC alone and with botanicals; Parthenium hysterophorus L. and Moringa oleifera L. on the digestibility indices and survival of Spodoptera litura (Fabricius) (Lepidoptera: Noctuidae). The P. hysterophorus extract at $50 \mathrm{mg}$ concentration was comparable to the alone application of emamectin benzoate in terms of reduced digestibility and survival of $S$. litura. Overall, $42.7 \%$ relative consumption rate (RCR), $74.3 \%$ efficiency of conversion of ingested food (ECI), 72.3\% efficiency of conversion of digested food (ECD), 87.5\% relative growth rate (RGR), $11.04 \%$ approximate digestibility (AD), and $47.6 \%$ assimilation rate (AR) were reduced after application of a mixture of emamectin benzoate and $P$. hysterophorus in comparison to control +ve treatment (untreated). The survival rate was also decreased by using this combination compared to the alone application of insecticide. These findings reflect $P$. hysterophorus extract's interference with the regulation of feeding and metabolism of $S$. litura. Further, the results promote $P$. hysterophorus extract in combination with emamectin benzoate for integrated management of $S$. litura.

Received | December 21,2020; Accepted | May 03, 2021; Published | June 28, 2021

*Correspondence | Muhammad Irfan Ullah, Department of Entomology, University of Sargodha, 40100, Sargodha, Pakistan; Email: Muhammad. irfanullah@uos.edu.pk

Citation | Ullah, M.I., S. Majeed, M. Arshad, N. Altaf, M. Luqman, A. Abdullah and M. Afzal. 2021. Effect of emamectin benzoate with leaf extracts of Parthenium hysterophorus and Moringa oleifera on the digestibility and survival indices of Spodoptera litura (Lepidoptera: Noctuidae). Sarhad Journal of Agriculture, 37(3): 830-838.

DOI | https://dx.doi.org/10.17582/journal.sja/2021/37.3.830.838

Keywords | Botanicals, Feeding indices, Spodoptera litura, Sustainable management, Emamectin benzoate
\end{abstract}

\section{Introduction}

Cpodopteralitura Fabricius (Lepidoptera: Noctuidae) $\mathcal{N}$ is a serious polyphagous insect pest (Ahmad et al., 2007; Liu et al., 2018). It is commonly known as tobacco caterpillar, armyworm and cutworm (Seth and Sharma, 2002). It is distributed worldwide, especially in tropical and temperate regions (Lin et al., 2019). It feeds on more than 120 host plants, including 112 cultivated food plants from 44 families (Ahmad et al., 2013; Abdullah et al., 2019). Major host plants of this pest are chilies, tobacco, cotton, okra, sunflower, soybeans, potato, lucerne, and castor (Sharma and Bisht, 2008). It may cause 26 to $100 \%$ economic losses in Pakistan's agro-ecological condition relying upon the specific to stage of crop and level of infestation (Khan et al., 2018). During 2003, the outbreak of $S$. litura occurred in Pakistan throughout the cotton belt and has resulted in heavy damage to crops (Ahmad et al., 2007). 
To manage the $S$. litura population in field use of synthetic insecticides is still being consider a good option (Ismail et al., 2017). Emamectin benzoate is a novel semi-synthetic bioinsecticide derived from the naturally occurring compound avermectin (Zaka et al., 2014). It is highly toxic against different insect pests, including; lepidopterans, thrips, fruit borer, cockroaches, and leafminer with both contact and stomach action (Muthukrishnan et al., 2012). It acts as a chloride channel activator that affects the nervous system of insects.

The use of these chemicals is wide-ranging that has provided an ideal environment of resistance development for the insects (Ahmad et al., 2008). Resistance development in S. litura against newer insecticides has been reported previously from different countries including Pakistan (Shad et al., 2012). Further, the harmful effect of chemicals on our environment and human is another threat (Kumar et al., 2013). Increasing risks with the insecticidal application, there is a need to use some other alternate and effective methods for the management of insect pests that should be safer for our environment and human health. Plants are the rich source of bioactive chemicals that can provide an alternative to synthetic chemicals (Qin et al., 2010). Many plants have insecticidal properties and are being used in integrated pest management programs (Mathesius, 2018; Trivedi et al., 2018). Moringa oleifera (Lam.), or drumstick tree' (Anwar and Bhanger, 2003), is a perennial tree and belongs to the family Moringaceae (Anwar et al., 2007; Ramachandran et al., 1980). Many bioactive proteins are present in this plant that have different biological activities such as lectins (de Lima Santos et al., 2009, 2014) named cMoL, which showed insecticidal activity against Anagasta kuebniella Zeller (Lepidoptera; Pyralidae). Parthenium bysterophorus L. (Family: Asteraceae), commonly known as chatak chandani, gajar ghas (Kumar et al., 2012), is a widely spread weed and has been used as an insect repellent (Wiesner et al., 2007). All plant's parts contain toxins known as sesquiterpene lactones (Datta and Saxena, 2001), parthenin and other phenolics (Oudhia, 2001) have insecticidal properties (Wu et al., 2016).

However, the increasing trend of plants use for high volumes of extract stock solution, inconsistent efficacy, and lower effectiveness against some target pests are challenging compared to synthetic insecticides (Isman, 2006; Pavela, 2015). About deficiencies in pesticides and plant extracts, new strategies for both methods are constantly sought. The joint effect of two substances showing synergistic effect has already been documented (Pavela, 2015). Previously plant extracts have been used in combination with synthetic insecticides (Harve and Kamath, 2014; Shaalan et al., 2005; Mohan et al., 2010). Silva et al. (2017) reported the synergistic and combined effect of deltamethrinOcimum basilicum against the $S$. frugiperda by lowering $80 \% \mathrm{LD}_{50}$ of the deltamethrin.

So far, no report is available on the combinatorial effect of insecticide with $P$. hysterophorus and $M$. oleifera against $S$. litura. Here, we determined the impact of emamectin benzoate alone and incombination with $M$. oleifera and P. hysterophorus, leaf extracts on digestibility indices of $S$. litura. We are expecting that the combinations of botanicals with insecticides will provide an alternative strategy in minimizing the insecticidal application, than alone application of insecticides and plant extracts.

\section{Materials and Methods}

\section{Insect culture}

The S. litura eggs were obtained from a field of soybean Glycine max (L.) in September, 2018 nearby University. The collected eggs were kept in glass Petri plates at $26 \pm 2{ }^{\circ} \mathrm{C}$ temperature and $64 \pm 5 \% \mathrm{RH}$. The neonate larvae were provided with artificial diet prepared by following the method of Sorour (Sorour et al., 2011). Pupal culture was shifted to plastic jars $(120 \mathrm{~mm} \times 116 \mathrm{~mm} \times 95 \mathrm{~mm})$ from Petri plates. On emergence, adult's culture was provided with a sugar solution (10\%). For oviposition, Muslin cloth strips ( $1 \mathrm{~cm}$ wide, $5-10 \mathrm{~cm}$ long) were hanged in oviposition plastic jars. The $F_{3}$ generation was used for further experiments.

\section{Plant extracts preparation}

Fresh and healthy leaves of $P$. hysterophorus and $M$. oleifera were obtained from a nearby field. Leaves were washed with distilled water and air-dried for 48 hours and then kept in oven at $50^{\circ} \mathrm{C}$ for 24 hours. The dried leaves were crushed in the electrical grinder (Moulinex, France) to make a fine powder. Ten-gram powder was added in $100 \mathrm{~mL}$ of methanol for making solution for 12 hours this solution was kept on an orbital shaker (OS-752 Pallscientific, Indonesia) to mix thoroughly. Then muslin cloth was used for filtering the solution and using Whatman No. 1 filter 
paper. After filtration, the remaining material was mixed with $100 \mathrm{~mL}$ methanol solvent, and again kept on electrical shaker and repeated the shaking procedure. For solvent evaporation, the solution was kept in a rotary vacuum evaporator $(\mathrm{BEV}-1001 \mathrm{~V}$, Henan, China). After drying, the prepared extracts were stored in refrigerator at $4^{\circ} \mathrm{C}$ temperature.

\section{Leaf dip bioassay}

The recommended dose $(0.5 \mathrm{ml} /$ liter of water $)$ of emamectin benzoate 1.9\% EC (GREEN ZONE), and $50 \mathrm{mg}$ of each plant extracts were used in this study. A preliminary experiment was performed to check the mortality of $S$. litura using two different concentrations $(25 \mathrm{mg}, 50 \mathrm{mg}$ ) of each plant extract. The higher concentration of each extract showed more significant toxicity against $S$. litura. So, we useda higher concentration of plant extracts in this study. An almost similar size of $3^{\text {rd }}$ and $4^{\text {th }}$ larval instars was tested and before the experiment, samesized and healthy larvae were selected and kept at starvation for 24 hours. The leaves (approximately $400 \mathrm{mg}$ ) of soybean G. max were obtained from the field. To remove the contaminants and dust particles from the collected leaves were washed with distilled water. The washed leaves were dipped in each solution for 10 seconds and dried at room temperature for 10 minutes. In each Petri plate placed the treated leaves and then single larvae was kept in each plate. The completely randomized design (CRD) was used to arrange the treatments. In control (+ve) treatment the untreated larvae were used, and in control (-ve) treatment only methanol was applied. Each treatment was replicated five times having five larvae in each replication.

\section{Data recording}

Data for larval weight and length, faeces weight and leaves' weight before and after 24 hours of feeding were recorded. Data for the survival rate of larvae were also recorded daily.

The digestibility indices were calculated by following formulas (Waldbauer, 1969);

Relative growth rate $(\mathrm{RGR})=\frac{B-A}{B} \times$ days

Relative consumption rate $(\mathrm{RCR})=\frac{D}{B} \times$ days

Efficiency of conversion of ingested food $(\mathrm{ECI})=\frac{B}{D} \times 100$
Effeciency of conersion of digested food (ECD) $=\frac{A}{E} \times 100$

$$
\begin{gathered}
\text { Approximate digestibility }(\mathrm{AD})=\frac{D-F}{D} \times 100 \\
\text { Assimilation rate }(\mathrm{AR})=R C R \times A D
\end{gathered}
$$

Where: $A=$ mean weight $(g)$ of the insects on last day; $\mathrm{B}=$ original mean weight of insects $(\mathrm{g}) ; \mathrm{D}=$ food biomass ingested (g) per insect); $\mathrm{E}=$ weight of food digested $(\mathrm{g})$ calculated by subtracting the weight of feces from the weight of food ingested, $F=$ feces biomass produced $(\mathrm{g})$ per insect.

\section{Statistical analysis}

Data normality was assessed before the analysis. Digestibility and survival data were analyzed using one-way analysis of variance (ANOVA) by keeping the treatment/chemicals as the main factors. Means were separated by using Fisher's least significant difference (LSD) all-pairwise comparison test. The data was analysedby using Minitab 17.0 software.

\section{Results and Discussion}

Spodoptera litura larvae gained maximum weight in control +ve (344.9mg) and controlled-ve (330.1mg) treatment over time. Emamectin benzoate plus $P$. hysterophorus $50 \mathrm{mg}$ reduced the larval weight more than control treatments, and the larval weight was found $266.8 \mathrm{mg}$ on the last day of feeding on treated leaves. However, larvae gained $277.7 \mathrm{mg}$ weight feeding on treated leaves with emamectin benzoate alone (Figure 1).

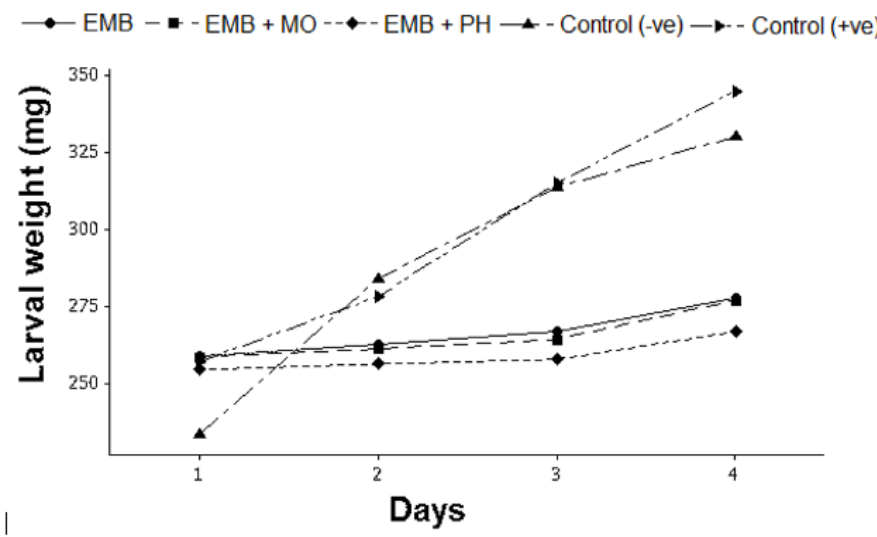

Figure 1: Effect of emamectin benzoate (EMB) insecticide alone and in combination with Parthenium hysterophorus (PH), and Moringa oleifera (MO), on larval weight of Spodoptera litura, control (+ve) is untreated larvae, control (-ve) is methanol application. 
The mixture of emamectin benzoate and P. hysterophorus reduced the maximum larval growth rate to $87.5 \%$ compared to the control +ve treatment. Similarly, the combined application of insecticide with $M$. oliefera reduced the larval growth rate to $82.5 \%$. While about $67.5 \%$ reduction in larval growth rate was occurwiththe application of insecticide alone. The consumption rate of $S$. litura larvae was reduced maximum up to $42.7 \%$ after applying a mixture of emamectin benzoate and $P$. hysterophorus in comparison to control +ve. However, larvae consumed $33.9 \%$ less when they fed on leaves treated insecticide alone. A similar trend in reducing ECI and ECD was found when larvae fed on treated leaves with a mixture of emamectin benzoate and P. hysterophorus. About 74.3\% ECI and 72.3\% ECD were reduced by applying this mixture application in comparison to control +ve. Combined application of emamectin benzoate and P. hysterophorus reduced maximum assimilation rate up to $47.6 \% \mathrm{com}-$ pared to control +ve. Maximum reduction (14.9\%) of $\mathrm{AD}$ rate was found by applying emamectin benzoate in comparison to control +ve. About $11.04 \% \mathrm{AD}$ rate was reduced using the mixture of emamectin benzoate with $M$. oliefera and $8.61 \%$ with $P$. hysterophorus (Table 1).

S. litura larvae's survival rate was higher (86.094.0\%) in both control treatments. However, with time, larvae's survival rate was decreased maximum in the treatment where emamectin insecticide plus $P$. hysterophorus extract was applied. Using emamectin alone and mixture of emamectin with $M$. oliefera extract, $6.7 \%$ larvae were survived onthe last day of exposure (Figure 2).

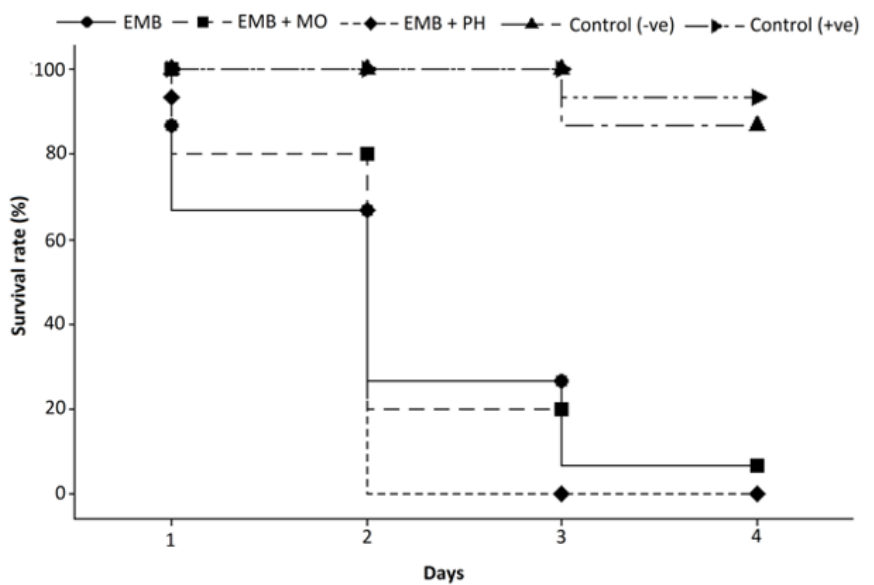

Figure 2: Survival rate of Spodoptera litura larvae after application of emamectin benzoate (EMB) alone and in combination with plant extracts, $P H=$ Parthenium hysterophorus, $M O=$ Moringa oleifera, untreated larvae were considered control (+ve) and methanol solvent was applied in control (-ve) treatment.
The comparison of plant extracts with insecticides has been immensely studied to minimize the use of synthetic insecticides, better toxicity, overcome insecticide resistance, and safer for the environment (López et al., 2005; Khater, 2012). We studied the toxicity of emamectin benzoate insecticides combined with $P$. hysterophorus and $M$. oleifera plant extracts against $S$. litura. Our findings showed that the combined effect of insecticide with $P$. bysterophorus negatively affected the $S$. litura in terms of growth disruption and survival rate. The $S$. litura larvae's growth is disrupted not only because of feeding inhibition (by the reduction in uptake of food and relative consumption rate) but also by digestibility (by reduction of $S$. litura efficiency in converting ingested food to growth) (War et al., 2011; Mahmoodi et al., 2020). Larval feeding inhibits and couldn't indigest food due to the presence of active principles in the plants (Jeyasankar and Premalatha, 2012). There is a disturbance in insect's physiology and its capability to digest food. However, detailed nutritional analyses are needed to understand the antifeedant effect of $P$. bysterophorus better. Our findings are similar to previous studies that reported feeding reduction of different insect pests using various plant extracts alone and in combination with insecticides. However, the reduction level was dependent upon species and dose (Silva et al., 2013; Olaitan and Abiodun, 2011; Nathan et al., 2005). After feeding on treated leaves, larvae showed variation in the conversion of ingested food into biomass. Results showed that the larvae fed on untreated leaves highly utilized the food compared to treated with insecticide plus plant extracts. Reduction in larvae's consumption rate due to application of botanicals was also reported by previous studies (Adel and Zaki, 2010; Ahmed et al., 2013).

Botanical insecticides have adverse effects on the insects' metabolic process; however, detailed study on these precise effect mechanisms is still needed. It could be either due to insects' inability to digest the food treated with botanical insecticides or decreased the conversion ability of ingested food into nutrients (Martinez and van Emden, 2001). In this study, the digestion (food nutrients absorption), rate of ingested food, assimilation rate was decreased due to feeding of larvae on leaves treated with emamectin plus $P$. bysterophorus. The combination of $P$. hysterophorus and synthetic insecticide suppressed the larvae growth and development of $S$. litura and reduced the body weight in terms of RGR. The plant extracts application proved 
Table 1: Effect (means $\pm S E$ ) of emamectin benzoate insecticide alone and in combination with plant extracts on relative consumption rate ( $R C R$ ), relative growth rate ( $R G R$ ), efficiency of conversion of ingested food (ECI), efficiency of conversion of digested food (ECD), approximate digestibility $(A D)$ and assimilation rate (AR) of Spodoptera litura, untreated larvae were considered control (+ve) and methanol solvent was applied in control (-ve) treatment.

$\begin{array}{lllllll}\text { Treatment } & \text { RGR } & \text { RCR } & \text { ECD (\%) } & \text { ECI (\%) } & \text { AR } & \text { AD (\%) } \\ \text { EMB } & 0.013 \pm 0.009 \mathrm{~b} & 0.413 \pm 0.012 \mathrm{~b} & 5.29 \pm 0.442 \mathrm{~b} & 3.17 \pm 0.274 \mathrm{~b} & 24.88 \pm 0.651 \mathrm{~b} & 60.05 \pm 0.496 \mathrm{c} \\ \mathrm{EMB}+\mathrm{MO} & 0.007 \pm 0.003 \mathrm{bc} & 0.377 \pm 0.007 \mathrm{bc} & 4.21 \pm 0.302 \mathrm{bc} & 2.66 \pm 0.175 \mathrm{~b} & 23.49 \pm 0.450 \mathrm{~b} & 62.76 \pm 0.340 \mathrm{~b} \\ \mathrm{EMB}+\mathrm{PH} & 0.005 \pm 0.007 \mathrm{c} & 0.358 \pm 0.008 \mathrm{c} & 3.17 \pm 0.552 \mathrm{c} & 2.04 \pm 0.357 \mathrm{~b} & 23.17 \pm 0.490 \mathrm{~b} & 64.47 \pm 0.055 \mathrm{~b} \\ \text { Control }(-\mathrm{ve}) & 0.037 \pm 0.018 \mathrm{a} & 0.602 \pm 0.004 \mathrm{a} & 11.02 \pm 0.545 \mathrm{a} & 7.72 \pm 0.314 \mathrm{a} & 42.02 \pm 0.536 \mathrm{a} & 69.45 \pm 0.578 \mathrm{a} \\ \text { Control }(+\mathrm{ve}) & 0.040 \pm 0.019 \mathrm{a} & 0.625 \pm 0.011 \mathrm{a} & 11.46 \pm 0.143 \mathrm{a} & 7.95 \pm 0.149 \mathrm{a} & 44.20 \pm 0.713 \mathrm{a} & 70.55 \pm 0.392 \mathrm{a} \\ \text { Significance } & 168.0^{* * *} & 211.0^{* * *} & 84.5^{* * *} & 117.0^{* * *} & 338.0^{* * * *} & 116^{* * * *}\end{array}$

**** shows the significance at $P=0.05$, means sharing similar letters are not significantly different at $P>0.05 ;$ EMB: emamectin benzoate, $P H$ : Parthenium hysterophorus, MO: Moringa oleifera.

poisonous for the growth of insects having insect growth regulator hormones disruption ability and insect stop feeding (Nasr et al., 2010), due to which insect ingestion becomes minimum and reduction in digestion occur (Shannag et al., 2015). Plant extracts application combined with other control methods has been considered a useful technique for the management of lepidopterous insect pests (Adel and Zaki, 2010; Arivoli and Tennyson, 2013; Ahmed et al., 2013).

Plant extracts act as a synergism when combined with insecticides (Mansour et al., 2012). The synergistic action could be due to the organism's least resistance ability and the toxic nature of the chemical composition (Chansang et al., 2018). Combining synthetic insecticides with plant material interrupts the different target sites (Madhu and Vijayan, 2010). Synthetic insecticides like emamectin benzoate cause the hormonal regulation of molting and developmental processes (Ishaaya et al., 2007), whereas plant extracts causeprevention or inhibition oviposition, growth hindering, repelling, and mimic juvenile hormones (Suwannayod et al., 2019).

According to Ali et al. (2017), botanicals, as alone or in combination with synthetic insecticides cause negative effects on the food consumption, growth, and development of the cabbage white butterfly, Pieris brassicae (L., 1758) (Lepidoptera: Pieridae). Combiningdifferent plant extracts with some selected synthetic chemicals showed highly toxic results against both larvae and adult Anopheles pharoensis (Mansour et al., 2010). Synergism is the process that helps in disrupting the integrity of an insect's midgut epithelial cells with specific enzymes delta- endotoxins fixation, due to which insects stop feeding and dead (Mhalla et al., 2018). The synergism effect of botanicals with insecticides could be cost-effective and long-lasting bio-pesticides (Shaalan et al., 2005). The combined application of synthetic and botanicals pesticides could be proved an ideal tool for managing resistance due to the repetition of conventional pesticides (Chandler et al., 2011).

\section{Conclusions and Recommendations}

In summary, it can be observed that $P$. hysterophorus extract can be used with emamectin benzoate insecticide in the integrated management of $S$. litura due to their negative effect on the digestibility and survival of the larvae. Mixing P. hysterophorus extract with insecticide may be a perfect solution to delay or reduce the insect resistance to synthetic insecticides. For the control of bollworms, the combination of these chemicals may be used as insecticidal formulation.

However, further study is needed to understand better action and cost-effectiveness of these combinations in the fields.

\section{Acknowledgments}

The authors thank the Department of Chemistry for providing a lab facility to prepare the plant extracts.

\section{Novelty Statement}

The findings showed that a mixture of emamectin benzoate and plant extracts, especially Parthenium bysterophorusat $50 \mathrm{mg}$ concentration, significantly reduce the digestibility and survival of Spodoptera 
litura. Thus, this combination of insecticides can be used in controlling this insect pest, which will be cost-effective.

\section{Author's Contribution}

Muhammad Irfan Ullah and Sana Majeed: experimented.

Muhammad Arshad, Nimra Altaf and Muhammad

Luqman: Wrote the first draft of the manuscripts.

Asad Abdullah: Designed the experiments.

Muhammad Afzal and Sana Majeed: Analyzed the data.

All authors read and approved the final manuscript.

\section{Conflict of interest}

The authors have declared no conflict of interest.

\section{References}

Abdullah, A., M.I. Ullah, A.B.M. Raza, M. Arshad and M. Afzal. 2019. Host plant selection affects biological parameters of Spodoptera litura. Pak. J. Zool., 51(6): 2117-2123. https://doi. org/10.17582/journal.pjz/2019.51.6.2117.2123

Adel,M.M.andF.N.Zaki.2010.Biological response of S. littoralis larvae to feeding on diet mixed with neem product at different concentrations. Arch. Phytopathol. Plant Prot., 43(8): 775-782. https://doi.org/10.1080/03235400802246697

Ahmad, M., A. Ghaffar and M. Rafiq. 2013. Host plants of leaf worm, Spodoptera litura Fabricius (Lepidoptera: Noctuidae) in Pakistan. Asian J. Agric. Biol., 1(1): 23-28.

Ahmad, M., A.H. Sayyed, M.A. Saleem and M. Ahmad. 2008. Evidence for field evolved resistance to newer insecticides in Spodoptera litura (Lepidoptera: Noctuidae) from Pakistan. Crop Prot., 27(10): 1367-1372. https://doi. org/10.1016/j.cropro.2008.05.003

Ahmad, M., M.I. Arif and M. Ahmad. 2007. Occurrence of insecticide resistance in field populations of Spodoptera litura (Lepidoptera: Noctuidae) in Pakistan. Crop Prot., 26(6): 809-817. https://doi.org/10.1016/j. cropro.2006.07.006

Ali, S., M.I. Ullah, M. Arshad, Y. Iftikhar, M. Saqib and M. Afzal. 2017. Effect of botanicals and synthetic insecticides on Pieris brassicae (L., 1758) (Lepidoptera: Pieridae). Turk. J. Entomol., 41(3): 275-284. https://doi. org/10.16970/entoted.308941

Anwar, F. and M. Bhanger. 2003. Analytical characterization of Moringa oleifera seed oil grown in temperate regions of Pakistan.J. Agric. Food Chem., 51(22): 6558-6563. https://doi. org/10.1021/jf0209894

Anwar, F., S. Latif, M. Ashraf and A.H. Gilani. 2007. Moringa oleifera: A food plant with multiple medicinal uses. Phytotherapy Research: Int. J. Dev. Pharmacol. Toxicol. Eval. Nat. Prod. Derivatives, 21(1): 17-25. https:// doi.org/10.1002/ptr.2023

Arivoli, S. and S. Tennyson. 2013. Antifeedant activity, developmental indices and morphogenetic variations of plant extracts against Spodoptera litura (Fab) (Lepidoptera: Noctuidae). J. Entomol. Zool. Stud., 1(4): 87-96.

Chandler, D., A.S. Bailey, G.M. Tatchell, G. Davidson, J. Greaves and W.P. Grant. 2011. The development, regulation and use of biopesticides for integrated pest management. Philos. Trans. R. Soc. B: Biol. Sci., 366(1573): 1987-1998. https://doi.org/10.1098/rstb.2010.0390

Chansang, A., D. Champakaew, A. Junkum, A. Jitpakdi, D. Amornlerdpison, A.K. Aldred, D. Riyong, A. Wannasan, J. Intirach and R. Muangmoon 2018. Synergy in the adulticidal efficacy of essential oils for the improvement of permethrin toxicity against Aedes aegypti L. (Diptera: Culicidae). Parasite. Vectors. 11: 417. https://doi.org/10.1186/s13071-018-3001-7

Datta, S. and D.B. Saxsena. 2001. Pesticidal properties of parthenin (from Parthenium bysterophorus) and related compounds. Pest Manage. Sci. Pestic Sci., 57(1): 95101. https://doi.org/10.1002/1526$4998(200101) 57: 1<95$ : : A I D PS248>3.0.CO;2-J

De lima Santos, N.D., K. Da Silwa Paixao, T.H. Napoleao, P.B. Trindade, M.R. Pinto, L.C.B.B. Coelho, E.A. Eiras, D.M.A.F. Navarro and P.M.G. Paiva. 2014. Evaluation of Moringa oleifera seed lectin in traps for the capture of Aedes aegypti eggs and adults under semi-field conditions. Parasitol. Res., 113(5): 1837-1842. https://doi.org/10.1007/s00436-014-3830-z

Harve, G. and V. Kamath. 2004. Larvicidal activity of plant extracts used alone and in combination with known synthetic larvicidal agents against Aedes aegypti. Indian J. Exp. Biol., 42(12): 1216-1219. 
Ishaaya, I., A. Barazani, S. Kontsedalov and A.R. Horowitz. 2007. Insecticides with novel modes of action: Mechanism, selectivity. Entomol. Res., 37 Cross-resist., 3: 148-152. https://doi. org/10.1111/j.1748-5967.2007.00104.x

Ismail, M., W. Wakil, N.H. Bashir, W. Hassan and U.W. Muhammad. 2017. Entomocidal effect of entomopathogenic fungus Beauveria bassiana and new chemistry insecticides against Spodoptera litura Fabricius (Noctuidae: Lepidoptera) under controlled conditions. Int. J. Agric. Inn. Res., 5(6): 2319-1473.

Isman, M., 2006. Botanical insecticides, deterrents, and repellents in modern agriculture and an increasingly regulated world. Annu. Rev. Entomol., 51: 45-66. https://doi.org/10.1146/ annurev.ento.51.110104.151146

Jeyasankar, A. and S. Premlatha. 2012. Bioefficacy of Solanum pseudocapsicum L. (Solanaceae) against black cutworm, Agrotisipsilon Hufnagel (Lepidoptera: Noctuidae). J. Biol. Sci., 12(3): 174-179. https://doi.org/10.3923/ jbs.2012.174.179

Khan, R.R., R.A. Ali, A. Ali, M. Arshad, S. Majeed, S.S.Ahmed and S.A. Khan.2018. Compatibility of entomopathogenic nematodes (Nematoda: Rhabditida) and the biocide, spinosad for mitigation of the armyworm, Spodoptera litura (F.) (Lepidoptera: Noctuidae). Egypt. J. Biol. Pest Cont., 28(1): 58-63. https://doi. org/10.1186/s41938-018-0063-y

Khater, H.F., 2012. Prospects of botanical biopesticides in insect pest management. Pharmacology, 3(12): 641-656. https://doi.org/10.5567/ pharmacologia.2012.641.656

Kumar, S., A.K. Sharma, S.S. Rawat, D.K. Jain and S. Ghosh. 2013. Use of pesticides in agriculture and livestock animals and its impact on environment of India. Asian J. Environ. Sci., 8(1): 51-57.

Kumar, S., G. Nair, A.P. Singh, S. Batra, S. Wahab and R. warikoo. 2012. Evaluation of the larvicidal efficiency of stem, roots and leaves of the weed, Parthenium hysterophorus (Family: Asteraceae) against Aedes aegypti L. Asian Pac. J. Trop. Dis., 2(5): 395-400. https://doi. org/10.1016/S2222-1808(12)60086-3

Lin, T., X. Li, B. Chen, P. Chen, M. Guo, X. Zhou and X. Cheng. 2019. Geographical origin identification of Spodoptera litura (Lepidoptera: Noctuidae) based on trace element profiles using tobacco as intermedium planted on soils from five different regions. Microchem. J., 146: 49-55. https://doi.org/10.1016/j. microc.2018.12.051

Liu, D., Z.Q. Jia, Y.C. Peng, C.W. Sheng, T. Tang, L. Xu, Z.J. Han and C.Q. Zhao. 2018. Toxicity and sublethal effects of fluralaner on Spodoptera litura Fabricius (Lepidoptera: Noctuidae). Pest. Bioch. Physiol., 152: 8-16. https://doi. org/10.1016/j.pestbp.2018.08.004

Lopez, Ó., J.G. Fernandez-bolanos and M.V. Gil. 2005. New trends in pest control: The search for greener insecticides. Green Chem., 7(6): 431442. https://doi.org/10.1039/b500733j

Madhu, S.K. and V.A. Vijayan. 2010. Evaluation of the larvicidal efficacy of extracts from three plants and their synergistic action with propoxur against larvae of the filarial vector Culex quinquefasciatus (Say). Toxicol. Environ. Chem. 92(1): 115-126. https://doi. org/10.1080/02772240902784242

Mahmoodi, L., F. Mehrkhou, N. Guz, M. Forouzan and R. Atlihan. 2020. Sublethal effects of three insecticides on fitness parameters and population projection of Brevicoryne brassicae (Hemiptera: Aphididae). J. Econ. Entomol., pp. 193. https://doi.org/10.1093/jee/toaa193

Mansour, S., R.F.A. Bakr, L.S. Hamouda and Mohamed. 2010. Toxic and synergistic properties of several botanical extracts against larval and adult stages of the mosquito, Anopheles pharoensis. Biopestic. Int. 6: 129-145.

Mansour, S.A., M.S. Foda and A.R. Aly. 2012. Mosquitocidal activity of two Bacillus bacterial endotoxins combined with plant oils and conventional insecticides. Indust. Crops Prod. 35(1): 44-52. https://doi.org/10.1016/j. indcrop.2011.06.001

Martinez, S.S. and H.F. Van Emden. 2001. Growth disruption, abnormalities and mortality of Spodoptera littoralis (Boisduval) (Lepidoptera: Noctuidae) caused by azadirachtin. Neotrop. Entomol., 30(1): 113-125. https://doi. org/10.1590/S1519-566X2001000100017

Mathesius, U., 2018. Flavonoid functions in plants and their interactions with other organisms. Plants, 7(2): 1-3. https://doi.org/10.3390/ plants7020030

Mesfin, E.G. Wondafrash and G. Terefe. 2012. Survival and feeding of African bollworm, Helicoverpa armigera (Hubner) (Lepidoptera: 
Noctuidae) affected by Neem, Azadirachta indica (A. Juss) extracts. World J. Agric. Sci., 8(3): 280-285.

Mhalla, D., D. Ben Farhat-Touzri, S. Tounsi and M. Trigui. 2018. Combinational effect of Rumex tingitanus (Polygonaceae) Hexane extract and Bacillus thuringiensis $\delta$-Endotoxin against Spodoptera littoralis (Lepidoptera: Noctuidae). Bio. Med. Res. Int., pp.1-7. https:// doi.org/10.1155/2018/3895834

Mohan, L., P. Sharma and S.N. Srivastava. 2010. Combination larvicidal action of Solanum xanthocarpum extract and certain synthetic insecticides against filarial vector, Culex quinquefasciatus (SAY). S. Asian J. Trop. Med. Public Health., 41(2): 311-319.

Muthukrishnana, N., K. Govindan and M. Visnupriya.2012. Effect of emamectin benzoate $5 \mathrm{SG}$ against thrips and fruit borer complex on grapevine. Madras Agric. J., 99: 871-876.

Nasr, H.M., M.E. Badawy and E.I. Rabea. 2010. Toxicity and biochemical study of two insect growth regulators, buprofezin and pyriproxyfen, on cotton leafworm Spodoptera littoralis. Pestic. Biochem. Physiol., 98(2): 198-205. https://doi. org/10.1016/j.pestbp.2010.06.007

Nathan, S.S., P.G. Chung and K. Murugan. 2005. Effect of biopesticides applied separately or togetheronnutritionalindicesofthericeleaffolder Cnaphalocrocis medinalis. Phytoparasit., 33(2): 187. https://doi.org/10.1007/BF03029978

Olaitan, A.F and T. Abiodun. 2011. Comparative toxicity of botanical and synthetic insecticides against major field insect pests of cowpea (Vigna unquiculata L.) Walp. J. Nat. Prod. Plant Res., 1(3): 86-95.

Oudhia, P., 2001. Parthenium hysterophorus: Traditional medicinal uses. Soc. Parthenium Manage. (SOPAM).

Pavela, R., 2015. Acute toxicity and synergistic and antagonistic effects of the aromatic compounds of some essential oils against Culex quinquefasciatus Say larvae. Parasitol. Res., 114: 3835-3853. https://doi.org/10.1007/s00436015-4614-9

Qin, W., S. Huang, C. Li, S. Chen and Z. Peng. 2010. Biological activity of the essential oil from the leaves of Piper sarmentosum Roxb.(Piperaceae) and its chemical constituents on Brontispa longissima (Gestro)(Coleoptera: Hispidae). Pestic. Biochem. Physiol., 96(3): 132-139. https:// doi.org/10.1016/j.pestbp.2009.10.006

Ramachandran, C., K. Peter and P. Gopalakrishnan. 1980. Drumstick (Moringa oleifera): A multipurpose Indian vegetable. Econ. Bot., 34(3): 276-283. https://doi.org/10.1007/ BF02858648

Santos, A.F., L.A. Luz, A.C. Argolo, J.A. Teixeira, P.M. Paiva and C.A. Coelho. 2009. Isolation of a seed coagulant Moringa oleifera Lectin. Process. Biochem., 44(4): 504-508. https://doi. org/10.1016/j.procbio.2009.01.002

Seth, R. and V.Sharma.2002. Growth, development, reproductive competence and adult behaviour of Spodoptera litura (Lepidoptera: Noctuidae) reared on different diets.

Shaalan, E.A.S., D.V.Canyon, M.W.F. Younes, H. Abdel-Wahab and A.H. Mansour. 2005. Effects of sub lethal concentrations of synthetic insecticides and Callitris glauscophylla extracts on the development of Aedes aegypti. J. Vector Ecol., 30(2): 295-298.

Shad, S.A., A.H. Sayyed, S. Fazal, M.A. Saleem, S.M. Zaka and M. Ali. 2012. Field evolved resistance to carbamates, organophosphates, pyrethroids, and new chemistry insecticides in Spodoptera litura Fab. (Lepidoptera: Noctuidae). J.Pest Sci. 85:153-162.https://doi.org/10.1007/ s10340-011-0404-z

Shannag, H.K., J.L. Capinera and N.M. Freihat. 2015. Effects of neem-based insecticides on consumption and utilization of food in larvae of Spodoptera eridania (Lepidoptera: Noctuidae). J. Insect Sci., 15(1): 152. https://doi.org/10.1093/ jisesa/iev134

Sharma, R.K. and R.S. Bisht. 2008. Antifeedant activity of indigenous plant extracts against Spodoptera litura Fabricius. J. Insect Sc. (Ludhiana). 21(1): 56-60.

Silva, L.B., J.C. Da Silva, B.E. Pavan, F.F. Pereira, K. Maggioni, H. Ligia and M.T. Peres. 2013. Insecticide irritability of plant extracts against Sitophilus zeamais. Afr. J. Agric. Res., 8(11): 978-983.

Silva, S., J.P.A. Rodrigues Da Cunha, S. Malfitano De Carvalho, C.H.S. Zandonadi, R.C. Martins and R. Chang. 2017. Ocimumbasilicum essential oil combined with deltamethrin to improve the management of Spodoptera frugiperda. Cienc. Agrotec., 41: 665-675. https://doi. org/10.1590/1413-70542017416016317

Sorour, M. A., O. Khamiss, A.S.E. El-Wahab, 
M.A.K. El-Sheikh and S. Abul-Ela. 2011. An economically modified semi-synthetic diet for mass rearing the Egyptian cotton leaf worm Spodoptera littoralis. J. Entomol., 4(3):118-123.

Suwannayod, S., K.L. Sukontason, J.K. Tomberlin, T. Chareonviriyaphap and K. Ukontason. 2019. Resistance risk of house fly (Musca domestica) and blow fly (Chrysomyamegacephala) to permethrin and deltamethrin in Chiang Mai province, Thailand. S. Asian J. Trop. Med. Publ. Health, (in preparation). 10(6): 178. https:// doi.org/10.3390/insects10060178

Trivedi, A., N. Nayak and J. Kumar. 2018. Recent advances and review on use of botanicals from medicinal and aromatic plants in stored grain pest management. J. Entomol. Zool. Stud., 6: 295-300.

Waldbauer, G., 1969. The consumption and utilization of food by insects. Adv. Insect Physiol., 5: 229-288. https://doi.org/10.1016/ S0065-2806(08)60230-1

War, A.R., M.G. Paulraj and Ignacimuthu. 2011. Synergistic activity of endosulfan with neem oil formulation against tobacco caterpillar Spodoptera litura (Fab.) (Lepidoptera: Noctuidae). J. Entomol., 8(6): 530-538. https:// doi.org/10.3923/je.2011.530.538

Weisner, W., I. Roth, A. Blievernicht, C. Buettner, T. Tessema, A. Goswami, I. Mewis and C. Ulrichs. 2007. Insecticidal Effects of Parthenium hysterophorus extracts rich in terpenoids and phenolic acids. Utilisation of Diversity in Land Use Systems: Sustainable Organic Appr. Meet Human Needs. pp. 9-11.

Wu, H.B., W.S.T.T. Wang, M.G. Liu, J.C. Qi, Feng and Y. Liu. 2016. Insecticidal activity of sesquiterpene lactones and monoterpenoid from the fruits of Carpesiumabrotanoides. Ind. Crops Prod., 92: 77-83. https://doi.org/10.1016/j. indcrop.2016.07.046

Zaka, S.M., N. Abbas, S.A. Shad and R.M. Shah. 2014. Effect of emamectin benzoate on life history traits and relative fitness of Spodoptera litura (Lepidoptera: Noctuidae). Phytoparasit., 42(4): 493-501. https://doi.org/10.1007/ s12600-014-0386-5 